\title{
Moderating the Relationship between Leadership and Commitment: An Empirical Study on Personality and Values
}

\author{
Thomas Meixner $^{1 *}$, Richard Pospisil ${ }^{2}$, Pavel Zufan ${ }^{3}$ \\ ${ }^{1 *}$ Faculty of Management and Economics, Mendel University, Brno, Czech Republic \\ ${ }^{2}$ Department of Economics and Management, Palacky University, Olomouc, Czech Republic \\ ${ }^{3}$ Faculty of Management and Economics, Mendel University, Brno, Czech Republic
}

\section{Keywords: Attracting and Retaining Talent, Employee \\ Commitment, Contemporary Leadership}

\section{Received}

09 March 2021

Received in revised form

12 April 2021

Accepted

13 April 2021

\section{*Correspondence:}

thomas.meixner@me.com

\begin{abstract}
Attracting and retaining talent is considered to be among the most crucial challenges for contemporary leadership. Building on this notion, the present paper aims to foster an understanding of the complex interplay between leadership practices and employee commitment. In these regards, the moderating role of personality variables and personal values is critically assessed. Building on a two-dimensional model of organizational commitment, the study proposes that leadership variables predict both emotional and behavioral commitment, with the relationship being moderated by personality variables as assessed throughout the Big Five framework and by personal values. To determine the validity of these hypotheses, an empirical, quantitative study was conducted following an observational design focusing on the employee perspective. Standardized questionnaires were utilized to assess the levels of commitment, the perceived leadership style of the participants' leaders, their personality and values. A total of $n=310$ individuals were recruited for participation in the empirical study, conducted by using an online survey. The statistical analyses showed a stable, significant correlation between the perception of leadership style and both types of organizational commitment, with leadership communication taking on a noteworthy role. The relevance of personality variables and values also could be confirmed, with their predictive power being more substantial for behavioral commitment. This was established using multiple linear regression analyses that compared the predictive power of the individual predictors.
\end{abstract}

CCIKD Publishing

As leaders and executives increasingly fight to not only attract the perfect talent for their firms, but also to retain them in a long-term collaboration (Griffith, 2019; Keller \& Meaney, 2017), leadership and management approaches increasingly change towards what Leclerc, Kennedy, and Campis (2020) or Bardy (2018) explain as human-centered approaches. This does not only 
translate to a shift in human resource practices (Lopez-Cabrales \& Valle-Cabrera, 2020), leadership styles (Buil, Martinez, \& Matute, 2019), technological solutions for the fostering of well-being at work (Haynes, 2017; Pretsch, Pretsch, Saretzki, Kraus, \& Grossmann, 2020; ), but also to a trend in management literature: Not only classical key performance indicators such as financial performance are shifted here in the focus of the literature on leadership and strategic management, but increasingly also ways to foster organizational commitment within firms, acknowledging the role of talents for the long-term success of modern enterprises (Esenyel, 2020; Jia, Liao, Van der Heijden, \& Guo, 2019). This high relevance of organizational commitment forms the foundation of the present study, which aims to analyze factors influencing this commitment in a multi-faceted perspective, considering both internal, thus personality-related variables on the one hand and leadership perception on the other hand. The present study's main contribution and its significance lie in the combined view described here - as leadership variables are considered predictors of organizational commitment alongside personality aspects such as the personality or the set of values (Schwartz, 2012). In general, acknowledging personal values as one of the potential predictors of organizational commitment is considered to be among the novelty factors of the present study.

\section{Emotional and Behavioral Commitment}

Organizational commitment or the attachment of employees to the company is described as "the psychological attachment of workers to their workplace" (Becker, Billings, Eveleth, \& Gilbert, 1996, p. 464). Becker et al. (1996) explain in this context that this employee retention is related to a variety of aspects of work relevant to companies. However, for the employees themselves, a higher degree of loyalty to the workplace can also be associated with positive results. The authors summarize the positive effects of increased retention by pointing out that employees who are strongly tied to companies are much less likely to leave their companies, leading to lower fluctuation rates and thus to cost savings and lower friction losses in the companies. Furthermore, employees with strong ties to the company tend to describe themselves as more satisfied with their work, which is also associated with an increased willingness and motivation to fulfill the work assignments given to them. This, according to Becker et al. (1996), ideally also leads to correspondingly better performance by employees who are more strongly bound to their company. This can also be explained by a reference to research results such as those of Macey and Schneider (2008) and Saks (2006), which also argue that employee engagement and retention are valuable predictors of work performance and thus represent one of the central tasks of managers. However, it must be emphasized that employee commitment does not depend exclusively on the manager and the company itself but that other aspects such as the personality or values of employees can also play a relevant role in this regard (Meixner, 2020a). In this context, it is explained that both person-immanent aspects such as personality or motivation and aspects of the environment (e.g., leadership or general work tasks and environments) can influence commitment and successively work performance.

\section{Leadership and Empowerment}

In this research, the concept of leadership before all is discussed using the example of the leadership tool empowerment. To classify this tool in a management context and thus in an operational situation, the underlying management approach must be described. Transformational 
leadership is defined by Bass (1999) and Avolio, Bass, and Jung (1999) as an approach that aims to create an emotional connection between the organization on the one hand and its employees on the other. It is a value transformation in which leaders who follow this leadership approach try to communicate the values of the organization to their employees in a way that encourages them to identify with the organization so that they will behave in the best interest of the organization even without instructions or incentives (Stewart, 2006). Core aspects of transformational leadership - such as Bass (1999) or Özaralli (2003) - are the charisma of the leader (Barbuto, 1997), individual consideration and leadership, intellectual stimulation of the employees and inspiration by the leader (Avolio \& Bass, 1995). Hater and Bass (1998) present an early definition of transformational leadership: "The dynamics of transformational leadership involve strong personal identification with the leader, joining in a shared vision of the future, or going beyond the self-interest exchange of rewards for compliance." (p. 695).

Transactional leadership (Bass, Avolio, \& Atwater, 1996; McCleskey, 2014; Sarros \& Santora, 2001), which is partly understood as the antithesis of transformational leadership, in turn, relies on precisely these reward incentives. Leadership is understood here as a transaction, i.e. as an exchange between the parties involved. A connection is to be achieved following this beginning by the fact that positive, thus in the sense of the enterprise suitable actions are recompensed by appropriate transactions, whereby here primarily, but not exclusively, the payment is located in the center. This can be seen, for example, in sales management systems with corresponding performance-based reward systems (Hayati, Atefi, \& Ahearne, 2018; MacKenzie, Podsakoff, \& Rich, 2001).

While these two management approaches pursue very different goals, authors such as Sarros and Santora (2001) or Judge and Piccolo (2004) emphasize that they are not two end points of a continuum, but rather two independently occurring management approaches, which can also be combined accordingly. For example, a strongly transformational management style does not exclude the possibility that a manager might use corresponding transactions to increase motivation.

In a similar way, it is also possible to refer to the corresponding motivation systems, whereby Deci and Ryan (2010) distinguish between intrinsic and extrinsic motivation. To increase the motivation and commitment of employees, different tools and communication approaches are used in both leadership styles, including storytelling, various leadership communication methods, and reward systems. However, this description of leadership styles typically focuses on positive approaches such as the ones mentioned earlier. However, practical leadership experiences show that less employee-oriented leadership styles such as passive-avoidant leadership (Jackson, Hutchinson, Peters, Luck, \& Saltman, 2013) also exist with accordingly negative effects on motivation and commitment.

As mentioned at the beginning, empowerment of employees is an approach of (often transformational) leadership in which they are given more control and responsibility (Chen, Kirkman, Kanfer, Allen, \& Rosen, 2007; Kark, Shamir, \& Chen, 2003. It should be noted that empowerment in itself is not only a leadership tool but - as Zimmerman (2000) explains - is seen as part of organizational psychology and as an aspect of group collaboration. Empowerment is discussed in this context, for example, in a medical or political context. One definition of empowerment is: "Empowerment may be seen as a process where individuals learn to see a closer correspondence between their goals and a sense of how to achieve them, and a relationship 
between their efforts and life outcomes" (Zimmerman, 2000, p. 43). In this context, it is discussed as a tool in medical practice, for example, to encourage patients to develop greater responsibility for their actions and thus strengthen the success of treatment.

Similarly, authors like Özaralli (2003) argue that transformational leadership can impact the perceived empowerment of staff. This leads to three basic mechanisms of action. The first mechanism is the perceived control over the situation or circumstances. Özaralli (2003) describes the second mechanism of empowerment as the perceived competence, which he also calls selfefficacy expectation (Bandura, 2010; Pajares, 1997). Finally, the internalization of goals is also to be understood as a partial aspect of empowerment.

The organizational environment can have a strong influence on the knowledge of empowerment. The underlying philosophy of this approach is the belief that existing traditional organizational practices could put employees in a state of powerlessness to use their full productive and creative potential, which could lead to passive attitudes and ineffective or mediocre performance (Özaralli, 2003). By changing or eliminating the conditions that lead to feelings of powerlessness, it is expected that employees would perform their productive and creative best. This is exactly what authors like Barbuto (2005) or Jensen and Bro (2018) consider to be a valuable task of transformational leadership.

\section{Personality and Values}

Personality researchers such as Goldberg (1990) stress the high individuality of humans regarding their characteristics and explain that these interindividual differences can have clear effects on the behavior of humans in different situations, for example even within the range of organizational behavior in the enterprise context. Values that Stahl (2013) describes as an important differentiating factor between people that a manager has to respond to are also described as influential by authors such as Schwartz (2012). These basic values can be divided into four basic value ranges, which seem to be suitable for adequately describing the values of people (Figure 1).

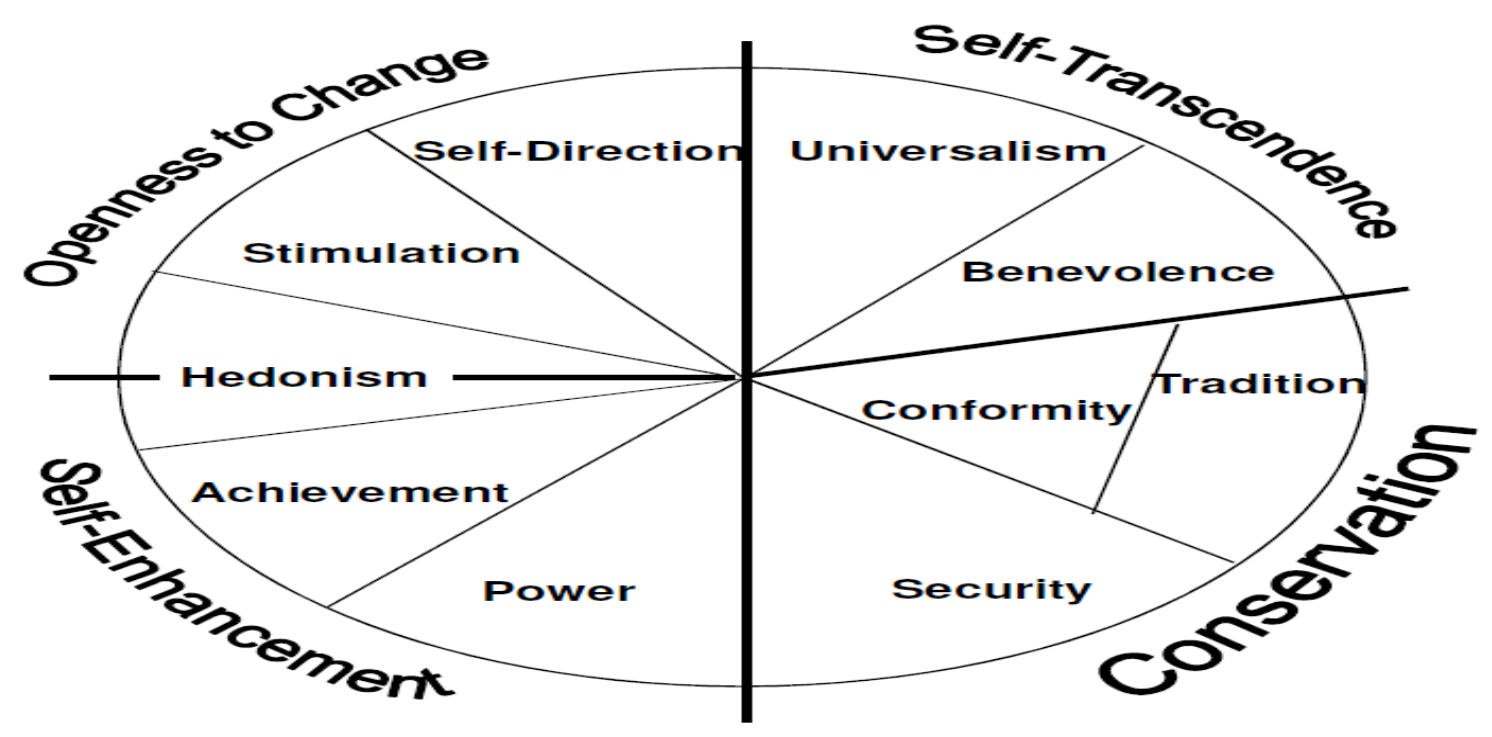

Figure 1. Values (Schwartz, 2012). 
These values, as Schwartz (2012) characterizes them, are differentiated into four clusters: openness to change, self-transcendence, conservation, and self-enhancement. The author argues these four clusters of values and their values themselves can showcase an individual's personal and professional values.

As an example of how values can affect behavior in the corporate context, we can refer to the fundamental value cluster of openness to change. Schwartz (2012) summarizes those attributes that show how willing people accept new situations and evaluate them positively. In the area of leadership, this openness is relevant, as Ma and Lee (2012) explain, especially with regard to the implementation of change processes, which require a correspondingly high degree of willingness on the part of both managers and employees to come to terms with such new situations. Stahl (2013) explains that all these aspects have to be appropriately appreciated by a successful manager to create positive conditions for the individuals in the group to be managed.

A related field of application is the management of diversity, which is described in the context of sustainable human resource management and leadership approaches. Particularly in the context of the increasing importance of diversity - for example, in relation to the origin, social position, or culture - of the employees and customers of many companies, a positive approach must be chosen in order to describe these inter-individual differences not (only) as a challenge or problem but to see them as a valuable contribution to increasing the corporate culture and the quality of cooperation. Serving leadership, as described by Stahl (2013) or Fischer, Stahl, Schettgen, and Schlipat (2019), seems to take on a role as an intellectual forerunner, especially with regard to the individualizing aspects of transformational leadership, and to be suited to meet these changing demands on managers accordingly.

\section{Research Framework}

As initially proposed within the framework of this study and the one presented within the work of Meixner (2020a), organizational commitment - with both its behavioral and emotional components - is dependent both on internal variables (such as the abovementioned values or the personality itself) and on external variables such as leadership. For the present work, the external environment is depicted throughout the lens of leadership and leadership communication only: While business environments are, of course, also shaped by other aspects (such as organizational culture, industry, human resource strategies, to name only a few), the present study shifted the focus on the established relationship between leadership and commitment. Leadership therein is assessed based on the leadership model proposed within the factor structure of the multifactor leadership questionnaire as proposed by Bass and Avolio (1996), who distinguish between transformational, transactional, and passive-avoidant leadership. The general state of research indicates that transformational leadership is mostly established as a predictor of commitment, whereas transactional leadership (Ebrahimi, Rezvani Chamanzamin, Rookhbaksh, \& Shavgan, 2017; Howell \& Avolio, 1993) is more critically discussed in these regards. Laissez-faire and avoidant approaches also show a distinct pattern in predicting motivation, emotional well-being, and commitment: If employees perceive their leaders as passive-avoidant, they typically also fare worse in regards to their perception of these variables. This set of external predictors, for the sake of this study, is supplemented by the assessment of leadership communication quality. The authors such as Arendt, Pircher Verdorfer, and Kugler (2019) and Juharyant (2020) argue that independent of the question of which leadership style is chosen, communication is among the 
most crucial challenges a leader is facing in the contemporary business environment. Clarity of communication and positive feedback towards the employees is generally understood to be among the most relevant predictors of long-term commitment. Less clear seems to be the research on the second concept supplementing the other leadership variables: empowerment. While Abualoush, Obeidat, Tarhini, and Badi (2018) and Rhee, Seog, Bozorov, and Dedahanov (2017) argue that empowering employees generally leads to favorable results, the concept still stems mostly from other fields, where positive results could also be shown. However, still little seems to be understood about how leaders and employees alike might benefit from the idea of empowerment and how the implementation of such approaches might strengthen employees' commitment to a certain firm.

\section{Research Gap and Objectives}

Organizational commitment, Meixner (2020a) confirmed, is a complex construct dependent both on environmental and internal aspects, thus, requiring in its prediction both variables concerning the leadership and corporate environment on the one hand and personal variables on the other hand. However, as it becomes visible with a gaze towards the relevant literature, research on the matter typically assesses only one side of this equation, therefore complicating how far these internal and external variables are connected with each other. The research gap addressed within the present paper lies in focus on leadership and personality variables. The assessment of personal values (Schwartz, 2012) as possible predictors of organizational commitment seems to be a novelty. While individual studies such as Cohen and Liu (2011), Kidron (1978), or Liu and Cohen (2010) exist and seemingly link personal values to organizational commitment, a holistic approach that involves not only values but also other relevant variables seem lacking within the existing literature. Given the different factors that potentially can influence organizational commitment (such as the leadership and personality variables mentioned earlier) and their complex interplay, a quantitative comparison of the predictive power of the individual sets of predictors seems like a highly relevant addition to the present state of research.

The present paper seeks to address this gap by adding both perspectives into one holistic analysis of the antecedents of organizational commitment, thus contributing to the state of research on organizational commitment and its antecessors. Therefore, a set of hypotheses is derived that will be assessed using an empirical approach.

Hypothesis 1: Leadership variables predict both emotional and behavioral commitment.

Hypothesis 2: Personality, values, and self-efficacy (thus, internal predictors) predict both emotional and behavioral commitment but have a positive effect on emotional commitment.

Hypothesis 3: Both internal and external predictors (see above) can account for unique variance in regard to emotional and behavioral commitment.

Hypothesis 4: It is possible to determine which set of predictors can explain the higher amounts of variance in regard to emotional and behavioral commitment.

The subsequent main objective of the proposed paper lies in fostering an understanding of the complex interplay of leadership, commitment, personality, and values as moderating factors. 


\section{Methods}

\section{Design and Sample}

The present study follows a non-experimental, correlative design. Given the nature of the research hypotheses presented above, mostly correlational analyses will focus on the present work. An online survey was conducted to assess these hypotheses, consisting of a set of measures described below. The main criterion variables of the study are the two aspects of organizational commitment - emotional and behavioral commitment (Meixner, 2020a). Predictors are divided into two distinct groups - internal and external ones. Internal predictors of organizational commitment are defined as personality, values, and self-efficacy perception. External predictors are aspects of transformational, transactional, passive-avoidant leadership, leadership communication quality, and empowerment. These aspects, however, are assessed from the employees' perspectives; thus, perceived leadership is chosen to be a set of possible predictors.

Sampling followed the general recommendations of Cohen (1992) in regards to minimal sample sizes. The researcher aimed to obtain a sample of satisfying size and representativity. Employees stemming from different companies in different fields were approached utilizing the extended professional network of the researcher. A total of $n=310$ participants took part in the quantitative survey. These individuals (for a detailed list information about the participants, including their respective industries and vocational models, see Table 1) are employees of different companies, assessing both their commitment and personality and - from their perspective - the behavior of their direct line leader. A majority of participants are full-time employed, with the most often named industry being the financial and insurance-related sector, followed by others (a category in which sectors not classified according to the depiction in Table 1 were clustered) and information and communication.

Table 1

Industries and Employment Models within the Sample

\begin{tabular}{|c|c|c|}
\hline Industry & Frequency & Percent \\
\hline Agriculture, Forestry, Fishery & 2 & .6 \\
\hline Mining and Quarrying & 1 & .3 \\
\hline Manufacturing & 22 & 7.1 \\
\hline Energy Supply/ Electricity, Gas, Steam and Air Conditioning & 5 & 1.6 \\
\hline Construction & 8 & 2.6 \\
\hline Wholesale and Retail Trade & 18 & 5.8 \\
\hline Transportation and storage & 22 & 7.1 \\
\hline Accommodation and Food Services & 3 & 1.0 \\
\hline Information and Communication & 29 & 9.4 \\
\hline Financial and Insurance Services & 44 & 14.2 \\
\hline Real Estate Services & 1 & .3 \\
\hline Freelance Professional, Scientiefic and Technical Services & 6 & 1.9 \\
\hline Administrative and Support Services & 20 & 6.5 \\
\hline Public Administration and Defence & 16 & 5.2 \\
\hline Education & 27 & 8.7 \\
\hline Social Work & 19 & 6.1 \\
\hline Human Health Services & 23 & 7.4 \\
\hline Arts, Culture and Entertainment & 5 & 1.6 \\
\hline Recreation/ Sports Services & 1 & .3 \\
\hline Other & 38 & 12.3 \\
\hline Total & 310 & 100.0 \\
\hline \multicolumn{3}{|l|}{ Employment Status } \\
\hline Full-Time Employment & 238 & 76.8 \\
\hline Regular Part-Time Employment & 67 & 21.6 \\
\hline Self-Employed but working in another company (e.g., client co & 5 & 1.6 \\
\hline Total & 310 & 100.0 \\
\hline
\end{tabular}




\section{Measures}

Emotional and behavioral commitment was assessed using the questionnaire developed by Meixner (2020a) based on a confirmatory factor analysis using pre-existing items. The validity of the measure was reported within Meixner (2020b) in regards to leadership. The items of the two scales were measured employing 5-point Likert scales.

For measurement of the general leadership approach, the multifactor leadership questionnaire (MLQ; Bass \& Avolio, 1996) was used. It uses a total of 9 sub-scales to assess the prevalence of transformational, transactional, and passive-avoidant leadership. Participants were asked to describe their direct line leader using these nine sub-scales and their total of 35 items. Ten additional items are used within the MLQ to assess leadership outcomes (effectiveness, satisfaction, extra effort), which were used as control variables indicating the validity of the measures in use.

The Perceived Leadership Communication Quality questionnaire (PLCQ, Schneider, Maier, Lovrekovic, \& Retzbach, 2015) was used to evaluate how participants assess the quality of communication experienced by their direct leader. A total of six items based on Likert scales is used to determine this variable.

A scale developed by Hayes (1994) was used to measure empowerment in the professional environment. The author developed the "Employee Empowerment Questionnaire" according to the principles of psychological questionnaire design and was checked concerning its factor structure and reliability. The 14 items of the original English-language test procedure are based on five-level Likert scales with the values "1 - strongly disagree" to "5 - strongly agree". Hayes explains that the psychometric properties of the test are suitable for use in practice (e.g., for measuring empowerment in an organization) and science. For the present study, 14 items were translated into German. To ensure the quality of this translation, a back-translation into English was then performed and compared with the original version.

The self-efficacy scale developed by Sherer and Adams (1983) with 17 items was used to measure self-efficacy. Six items relating to self-efficacy in social situations were not used in this study. The authors describe the questionnaire as a reliable and valid method for measuring selfefficacy, which was able to demonstrate, for example, by the medium-high correlations to related constructs such as personal control convictions or control focus. This originally English-language questionnaire was also translated into German and used accordingly, analogous to the procedure for the scale for recording the experienced empowerment.

The personality was assessed using the Big Five Inventory (BFI; Rammstedt \& John, 2007) in the short, ten-item form. The authors argue that the short-version provides similar psychometric properties as the significantly longer versions, thus allowing the usage within scientific research.

Personal values (Schwartz, 2012) were assessed using a work context perspective. While measures such as the PVQ (Cieciuch \& Schwartz, 2012) measure general values of individuals, the Work Values Questionnaire (WVQ; Avallone, Farnese, Pepe, \& Vecchione, 2010) used throughout this study shifts the focus to work-related values, building on the initial concept described by Schwartz (2012). Concerning workplace values, a total of six clusters was identified by Avallone et al. (2010): power achievement, benevolence universalism, conformity tradition, self-direction, hedonism, and security. Based on the empirical evaluation of the questionnaire, the author argues that the WVQ "may be considered a valid and reliable instrument." (Avallone, 
2010, p. 70). The six dimensions of the WVQ are measured using 30 items with a 5-point Likert scale.

\section{Results}

\section{Pre-Analyses}

While the present study built on previously pre-evaluated scales and measurements, the reliability analyses were conducted. These analyses were used to assess whether the computation of the scales according to the test manuals is indicated and therefore to build the foundation of the subsequent analyses (de Vet, Mokkink, Mosmuller, \& Terwee, 2017). Table 2 shows that the Cronbach Alpha indices are strong indicators of scale reliability. This analysis was conducted for all scales except for the Big Five scales, as due to their low number of items ( 2 items per scale) no meaningful results can be derived from a reliability analysis based on the Cronbach Alpha method (de Vet et al., 2017; Tavakol \& Dennick, 2011; Vaske, Beaman, \& Sponarski, 2017).

Table 2

Reliability Indices of Scales

\begin{tabular}{|c|c|c|c|}
\hline & & Cronbach $\alpha$ & No. Of Item \\
\hline \multirow{5}{*}{ Aspects of Transformational Leadership } & Idealized Attributes & .80 & 4 \\
\hline & Idealized Behaviors & .82 & 4 \\
\hline & Inspirational Motivation & .83 & 4 \\
\hline & Intellectual Stimulation & .80 & 4 \\
\hline & Individual Consideration & .78 & 4 \\
\hline \multirow{2}{*}{ Aspects of Transactional Leadership } & Contingent Reward & .78 & 4 \\
\hline & Management by Exception (active) & .72 & 4 \\
\hline \multirow{2}{*}{ Aspects of Passive Avoidant Leadership } & Management by Exception (passive) & .70 & 4 \\
\hline & Laissez-Faire & .78 & 4 \\
\hline \multirow{3}{*}{ Outcomes of Leadership } & Outcomes: Extra Effort & .79 & 3 \\
\hline & Outcomes: Effectiveness & .83 & 4 \\
\hline & Outcomes: Satisfaction & .79 & 2 \\
\hline \multirow{2}{*}{ Organizational Commitment } & Emotional Commitment & .92 & 20 \\
\hline & Behavioral Commitment & .87 & 16 \\
\hline \multirow{9}{*}{ Values } & Power Achievement & .80 & 6 \\
\hline & Benevolence Universalism & .79 & 6 \\
\hline & Conformity Tradition & .71 & 6 \\
\hline & Self Direction Stimulus & .82 & 6 \\
\hline & Hedonism & .70 & 3 \\
\hline & Security & .70 & 3 \\
\hline & Perceived Leadership Communication & .90 & 6 \\
\hline & Empowerment & .85 & 14 \\
\hline & Self Efficacy & .87 & 17 \\
\hline
\end{tabular}

\section{Descriptive Results}

Table 3 shows the relevant psychometric indicators (means, standard deviations, and range) of the scales used within the study. The same values supplement this for the big five scales that were not reported due to their low number of items. 
Table 3

Descriptive Statistics

\begin{tabular}{|c|c|c|c|c|c|}
\hline & & Min & Max & $M$ & $S D$ \\
\hline \multirow{2}{*}{ Commitment } & Emotional Commitment & 1.30 & 5.00 & 3.40 & .68 \\
\hline & Behavioral Commitment & 1.44 & 5.00 & 3.34 & .70 \\
\hline \multirow{5}{*}{ Aspects of Transformational Leadersh } & Idealized Attributes & 1.00 & 5.00 & 3.30 & .83 \\
\hline & Idealized Behavior & 1.00 & 5.00 & 3.38 & .82 \\
\hline & Inspirational Motivation & 1.00 & 5.00 & 3.43 & .85 \\
\hline & Intellectual Inspiration & 1.00 & 5.00 & 3.31 & .81 \\
\hline & Individual Consideration & 1.00 & 5.00 & 3.31 & .85 \\
\hline \multirow{2}{*}{$\begin{array}{l}\text { Aspects of Transactional } \\
\text { Leadership }\end{array}$} & Contingent Reward & 1.00 & 5.00 & 3.36 & .76 \\
\hline & Management by Exception (Active, & 1.00 & 5.00 & 3.04 & .78 \\
\hline \multirow{2}{*}{ Aspects of Passive Avoidant Leadersh } & Management by Exception (Passiv $\epsilon$ & 1.00 & 5.00 & 2.66 & .82 \\
\hline & Laissez Faire & 1.00 & 5.00 & 2.59 & .91 \\
\hline \multirow{4}{*}{ Leadership Outcomes } & Extra Effort & 1.00 & 5.00 & 3.20 & .86 \\
\hline & Effectiveness & 1.00 & 5.00 & 3.36 & .83 \\
\hline & Satisfaction & 1.00 & 5.00 & 3.41 & 1.02 \\
\hline & Overall Outcomes & 1.00 & 5.00 & 3.32 & .83 \\
\hline \multirow{3}{*}{ Leadership Styles } & Transformational Leadership & 1.00 & 5.00 & 3.34 & .75 \\
\hline & Transactional Leadership & 1.00 & 5.00 & 3.20 & 61 \\
\hline & Passive Avoidant & 1.00 & 4.75 & 2.62 & .80 \\
\hline \multirow{5}{*}{ Big Five } & BFI Extraversion & 1.00 & 5.00 & 3.40 & .76 \\
\hline & BFI Agreeableness & 2.00 & 5.00 & 3.51 & .71 \\
\hline & BFI Conscientiousness & 1.00 & 5.00 & 3.69 & .82 \\
\hline & BFI Neuroticism & 1.00 & 5.00 & 2.50 & .82 \\
\hline & BFI Openness & 1.00 & 5.00 & 3.40 & .70 \\
\hline \multirow{9}{*}{ Values } & Power Achievement & 1.00 & 5.00 & 3.32 & .73 \\
\hline & Benevolence Universalism & 1.00 & 5.00 & 3.76 & .64 \\
\hline & Conformity Tradition & 1.00 & 4.67 & 3.03 & .62 \\
\hline & Self Direction Stimulus & 1.00 & 5.00 & 3.73 & .63 \\
\hline & Hedonism & 1.00 & 5.00 & 3.87 & .71 \\
\hline & Security & 1.00 & 5.00 & 3.91 & .75 \\
\hline & $\begin{array}{l}\text { Perceived Leadership } \\
\text { Communication Quality }\end{array}$ & 1.00 & 5.00 & 3.51 & .93 \\
\hline & Empowerment & 1.36 & 5.00 & 3.39 & .62 \\
\hline & Self Efficacy & 2.12 & 5.00 & 3.67 & .61 \\
\hline
\end{tabular}

The relationship between the leadership outcomes measured by the MLQ and the aspects of commitment measured using the questionnaire developed by Meixner (2020a) was analyzed. This analysis is a measure of general validity, as leadership outcomes and commitment are closely related variables, which implies that a high correlation between them might indicate strong validity (Carlson \& Herdman, 2012; Russell, 1978). The correlations should be high enough to showcase the connection between the scales and low enough to indicate distinct scales. The validity of the measures was confirmed by correlations ranging from $r=.42$ until $r=.55$ and considered for the subsequent analyses. Table 4 shows the results of the analysis of the commitment scale.

Table 4

Validity of Commitment Scores (own data)

\begin{tabular}{llll}
\hline & & Emotional Commitment & Behavioral Commitment \\
\hline Extra Effort & Pearson Correlation & $.50^{* *}$ & $.42^{* * *}$ \\
& Sig. (2-tailed) & .00 & .00 \\
Effectiveness & & $.51^{* *}$ & $.49^{* *}$ \\
& Pearson Correlation & .00 & $.00^{* *}$ \\
Satisfaction & Sig. (2-tailed) & $.55^{* *}$ & $.50^{* *}$ \\
& Pearson Correlation & .00 & .00 \\
\hline
\end{tabular}




\section{Assessment of the Framework}

An analysis was conducted showing the correlations between external predictors of organizational commitment and the two aspects of organizational commitment itself. External predictors of commitment as defined within this study are leadership, perceived leadership communication quality, and empowerment. Table 5 shows the pairwise correlations between those variables. As presented in Table 5, positive relationships (as assumed) were found between aspects of transformational leadership and both types of commitment. The same (although typically with lower effect sizes) was found for transactional leadership, which is positively related to commitment outcomes. On the other hand, passive avoidant leadership behaviors correlate negatively with both types of organizational commitment, proving the initial assumption. Apart from these results based on the MLQ model, leadership communication and empowerment correlate positively with emotional and behavioral commitment.

Table 5

Pairwise Correlations between Leadership and Commitment

\begin{tabular}{|c|c|c|c|c|}
\hline & & & Emotional Commitment & Behavioral Commitment \\
\hline \multirow{10}{*}{$\begin{array}{l}\text { Aspects of Transformational } \\
\text { Leadership }\end{array}$} & \multirow{2}{*}{ Idealized Attributes } & Pearson Correlation & $.56^{* *}$ & $.47^{* *}$ \\
\hline & & Sig. (2-tailed) & .00 & .00 \\
\hline & \multirow[t]{2}{*}{ Idealized Behavior } & Pearson Correlation & $.57^{* *}$ & $.48^{* *}$ \\
\hline & & Sig. (2-tailed) & .00 & .00 \\
\hline & \multirow[t]{2}{*}{ Inspirational Motivation } & Pearson Correlation & $.55^{* *}$ & $.46^{* *}$ \\
\hline & & Sig. (2-tailed) & .00 & .00 \\
\hline & \multirow[t]{2}{*}{ Intellectual Inspiration } & Pearson Correlation & $.47^{* *}$ & $.40^{* *}$ \\
\hline & & Sig. (2-tailed) & .00 & .00 \\
\hline & \multirow[t]{2}{*}{ Individual Consideration } & Pearson Correlation & $.52^{* *}$ & $.42^{* *}$ \\
\hline & & Sig. (2-tailed) & .00 & .00 \\
\hline \multirow{4}{*}{$\begin{array}{l}\text { Aspects of Transactional } \\
\text { Leadership }\end{array}$} & \multirow{2}{*}{ Contingent Reward } & Pearson Correlation & $.51^{* *}$ & $.44^{* *}$ \\
\hline & & Sig. (2-tailed) & .00 & .00 \\
\hline & \multirow{2}{*}{$\begin{array}{l}\text { Management by Exception } \\
\text { (Active) }\end{array}$} & Pearson Correlation & .09 & -.01 \\
\hline & & Sig. (2-tailed) & .09 & .86 \\
\hline \multirow{4}{*}{$\begin{array}{l}\text { Aspects of Passive Avoidant } \\
\text { Leadership }\end{array}$} & \multirow{2}{*}{$\begin{array}{l}\text { Management by Exception } \\
\text { (Passive) }\end{array}$} & Pearson Correlation & $-.26^{* * *}$ & $-.36^{* *}$ \\
\hline & & Sig. (2-tailed) & .00 & .00 \\
\hline & \multirow{2}{*}{ Laissez Faire } & Pearson Correlation & $-.29^{* *}$ & $-.34^{* *}$ \\
\hline & & Sig. (2-tailed) & .00 & .00 \\
\hline \multirow{6}{*}{ Outcomes of Leadership } & \multirow{2}{*}{ Extra Effort } & Pearson Correlation & $.50^{* *}$ & $.42^{* *}$ \\
\hline & & Sig. (2-tailed) & .00 & .00 \\
\hline & \multirow[t]{2}{*}{ Effectiveness } & Pearson Correlation & $.51^{* *}$ & $.49^{* *}$ \\
\hline & & Sig. (2-tailed) & .00 & .00 \\
\hline & \multirow[t]{2}{*}{ Satisfaction } & Pearson Correlation & $.55^{* *}$ & $.50^{* *}$ \\
\hline & & Sig. (2-tailed) & .00 & .00 \\
\hline \multirow{10}{*}{ Leadership Styles } & \multirow{2}{*}{ Transformational Leadership } & Pearson Correlation & $.59^{* *}$ & $.50^{* *}$ \\
\hline & & Sig. (2-tailed) & .00 & .00 \\
\hline & \multirow[t]{2}{*}{ Transactional Leadership } & Pearson Correlation & $.38^{* *}$ & $.26^{* *}$ \\
\hline & & Sig. (2-tailed) & .00 & .00 \\
\hline & \multirow[t]{2}{*}{ Passive Avoidant } & Pearson Correlation & $-.30^{* *}$ & $-.38^{* *}$ \\
\hline & & Sig. (2-tailed) & .00 & .00 \\
\hline & Perceived Leadership & Pearson Correlation & $.60^{* *}$ & $.55^{* *}$ \\
\hline & Communication Quality & Sig. (2-tailed) & .00 & .00 \\
\hline & \multirow[t]{2}{*}{ Empowerment } & Pearson Correlation & $.52^{* *}$ & $.44^{* *}$ \\
\hline & & Sig. (2-tailed) & .00 & .00 \\
\hline
\end{tabular}

**Correlation is significant at the 0.01 level (2-tailed). 
To conclude these bi-variate, pairwise correlations, a multiple linear regression analysis was conducted following a stepwise approach. This stepwise regression aimed to identify the amount of variance that could be explained based on these leadership variables regarding emotional and behavioral commitment. However, while for the pairwise correlations, more variables were included, the regression analyses will omit the combined scores for transformational, transactional, and passive avoidant leadership, as their individual subscales represent them. Also, leadership outcomes are not considered predictors in this model. They are instead discussed to be correlates of organizational commitment than predictors, with them being outcomes of leadership themselves. Thus, the set of potential predictors entered into the stepwise regression model consists of the individual scales derived from the MLQ, the perceived leadership communication quality, and the perceived empowerment. Analyses are conducted separately for emotional and behavioral commitment. Table 5 shows the results for emotional commitment.

The analysis shows that for emotional commitment, a total of $R^{2}=.45$ of variance can be explained. Thereby the model follows four steps, with perceived leadership communication quality in the first step leading to the most considerable leap in $\mathrm{R}^{2}$. Additionally, empowerment, management by exception (passive), and inspirational motivation explained further variance, cumulating in the total variance explanation, as shown in Table 6.

Similar results were found for the behavioral commitment where a set of three predictors was able to account for $R^{2}=.40$ of variance, with - again - perceived leadership communication quality being the first predictor included in the model with the most considerable change in $\mathrm{R}^{2}$. Table 6

Regression for Leadership Variables and Emotional Commitment

\begin{tabular}{|c|c|c|c|c|c|}
\hline & & $B$ & $S E B$ & $\beta$ & $p$ \\
\hline \multicolumn{6}{|l|}{ Step 1} \\
\hline & Constant & 1.86 & .12 & & $<.001$ \\
\hline & Perceived Leadership Communication Quality & 0.44 & .03 & .60 & $<.001$ \\
\hline \multicolumn{6}{|l|}{ Step 2} \\
\hline & Constant & 1.24 & .16 & & $<.001$ \\
\hline & Perceived Leadership Communication Quality & 0.32 & .03 & .44 & $<.001$ \\
\hline & Empowerment & 0.27 & .05 & .27 & $<.001$ \\
\hline \multicolumn{6}{|l|}{ Step 3} \\
\hline & Constant & 1.72 & .20 & & $<.001$ \\
\hline & Perceived Leadership Communication Quality & 0.32 & .03 & .43 & $<.001$ \\
\hline & Empowerment & 0.27 & .05 & .24 & $<.001$ \\
\hline & Management by Exception (Passive) & -0.13 & .03 & -.16 & $<.001$ \\
\hline \multicolumn{6}{|l|}{ Step 4} \\
\hline & Constant & 1.63 & .20 & & \\
\hline & Perceived Leadership Communication Quality & 0.23 & .04 & .31 & $<.001$ \\
\hline & Empowerment & 0.22 & .05 & .20 & $<.001$ \\
\hline & Management by Exception (Passive) & -0.13 & .03 & -.16 & $<.001$ \\
\hline & Inspirational Motivation & 0.16 & .04 & .20 & $<.001$ \\
\hline
\end{tabular}

Note. $R^{2}=.36$ for Step $1 ; \Delta R^{2}=.05$ for Step $2 ; \Delta R^{2}=.02$ for Step $3 ; \Delta R^{2}=.00$ for Step $4 ;(p<.01)$.

Additionally, management by exception (passive), and empowerment proved significant predictors of behavioral commitment (see Table 7). 
Table 7

Regression for Leadership Variables and Behavioral Commitment

\begin{tabular}{|c|c|c|c|c|c|}
\hline & & $B$ & $S E B$ & $\beta$ & $p$ \\
\hline \multicolumn{6}{|l|}{ Step 1} \\
\hline & Constant & 1.87 & .13 & & $<.001$ \\
\hline & Perceived Leadership Communication Quality & 0.42 & .03 & .55 & $<.001$ \\
\hline \multicolumn{6}{|l|}{ Step 2} \\
\hline & Constant & 2.65 & .17 & & $<.001$ \\
\hline & Perceived Leadership Communication Quality & 0.39 & .03 & .51 & $<.001$ \\
\hline & Management by Exception (Passive) & -0.25 & .03 & -.29 & $<.001$ \\
\hline \multicolumn{6}{|l|}{ Step 3} \\
\hline & Constant & 2.25 & .22 & & $<.001$ \\
\hline & Perceived Leadership Communication Quality & 0.32 & .04 & .43 & $<.001$ \\
\hline & Management by Exception (Passive) & -0.23 & .03 & -.27 & $<.001$ \\
\hline & Empowerment & 0.17 & .06 & .15 & $<.005$ \\
\hline
\end{tabular}

Note. $R^{2}=.30$ for Step $1 ; \Delta R^{2}=.08$ for Step $2 ; \Delta R^{2}=.01$ for Step $3 ;(p<.01)$.

Therefore, the main difference towards the emotional commitment seems to lay in the aspect of inspirational motivation, which only seems to predict the emotional aspects of commitment. The results of both regression analyses are compared in Figure 2, showing the overall variance explanation and the contribution of the individual predictors.

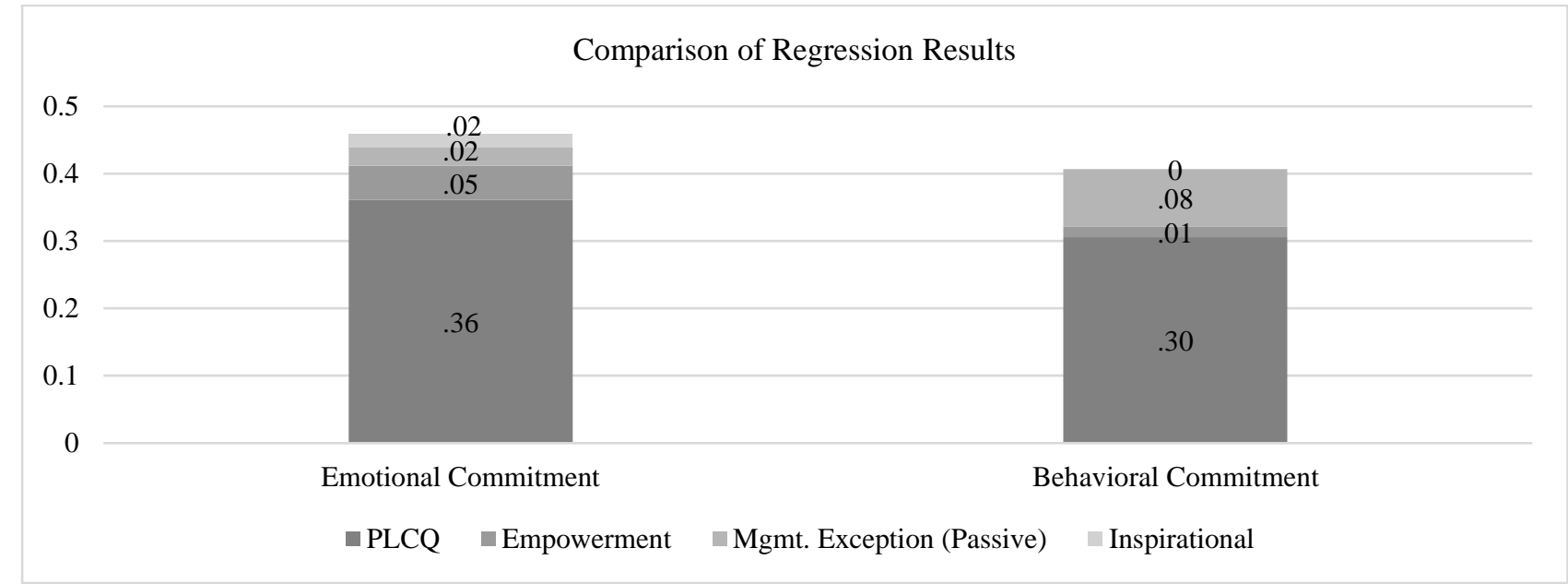

Figure 2. Comparison of regression results, leadership aspects

In a similar vein, analyses were conducted for the second potential set of predictors, shifting the focus towards the personal antecedents of organizational commitment. In these regards, the five personality factors, the values defined by Schwartz (2012), and perceived self-efficacy were considered potential antecedents of organizational commitment. In a first step to present an overview, again, bi-variate pairwise correlations were calculated (Table 8). 
Table 8

The Correlation Results of Personality and Commitment

\begin{tabular}{|c|c|c|c|c|}
\hline & & & Emotional Commitment & Behavioral Commitment \\
\hline \multirow{10}{*}{ Big Five } & \multirow{2}{*}{ BFI Extraversion } & Pearson Correlation & $.13^{*}$ & .08 \\
\hline & & Sig. (2-tailed) & .02 & .13 \\
\hline & \multirow[t]{2}{*}{ BFI Agreeableness } & Pearson Correlation & $.21^{* *}$ & $.16^{* *}$ \\
\hline & & Sig. (2-tailed) & .00 & .00 \\
\hline & \multirow[t]{2}{*}{ BFI Conscientiousness } & Pearson Correlation & $.24^{* *}$ & $.20^{* *}$ \\
\hline & & Sig. (2-tailed) & .00 & .00 \\
\hline & \multirow[t]{2}{*}{ BFI Neuroticism } & Pearson Correlation & $-.20^{* *}$ & $-.15^{* *}$ \\
\hline & & Sig. (2-tailed) & .00 & .00 \\
\hline & \multirow[t]{2}{*}{ BFI Openness } & Pearson Correlation & $.24^{* *}$ & $.16^{* *}$ \\
\hline & & Sig. (2-tailed) & .00 & .00 \\
\hline \multirow{15}{*}{ Values } & \multirow{2}{*}{ Power Achievement } & Pearson Correlation & $.19^{* *}$ & .06 \\
\hline & & Sig. (2-tailed) & .00 & .29 \\
\hline & \multirow[t]{2}{*}{ Benevolence Universalism } & Pearson Correlation & $.23^{* *}$ & $.14^{*}$ \\
\hline & & Sig. (2-tailed) & .00 & .01 \\
\hline & \multirow[t]{2}{*}{ Conformity Tradition } & Pearson Correlation & -.00 & -.03 \\
\hline & & Sig. (2-tailed) & .98 & .58 \\
\hline & \multirow{3}{*}{ Self Direction Stimulus } & & & \\
\hline & & Pearson Correlation & .30 & $.21^{\prime \prime}$ \\
\hline & & Sig. (2-tailed) & .00 & .00 \\
\hline & \multirow[t]{2}{*}{ Hedonism } & Pearson Correlation & $.24^{* *}$ & $.14^{*}$ \\
\hline & & Sig. (2-tailed) & .00 & .01 \\
\hline & \multirow[t]{2}{*}{ Security } & Pearson Correlation & $.25^{* *}$ & $.26^{* *}$ \\
\hline & & Sig. (2-tailed) & .00 & .00 \\
\hline & \multirow{2}{*}{ Self Efficacy } & Pearson Correlation & $.31^{* *}$ & $.29^{* * *}$ \\
\hline & & Sig. (2-tailed) & .00 & .00 \\
\hline
\end{tabular}

Significant correlations present themselves between several personality factors (typically positive correlations except for neuroticism, that - as is usually the case, correlates negatively with both aspects of commitment and commitment. The situation presents itself in a complex light regarding the values: The desire for power achievement is positively linked to emotional commitment. However, no link to behavioral commitment was identified. No correlations were also found between the value cluster of conformity and tradition on the one hand and the two types of organizational commitment on the other hand. For the remaining values, positive correlations of small and medium effect sizes could be confirmed. This pairwise approach formed the foundation of two multiple, linear regression analyses following the same logic as the ones presented above. Possible predictors for these stepwise analyses were the personality factors, the values and the measure of self-efficacy. The analysis was conducted for both aspects of organizational commitment. Table 9 shows the results of the analysis for emotional commitment. It could be shown that self-efficacy (as the strongest and primal predictor), followed by the value cluster self-direction and the personality factor openness, explained a total of $R^{2}=.13$ of the total variance in regards to the criterion. 
Table 9

Regression for Personality Variables and Emotional Commitment

\begin{tabular}{|c|c|c|c|c|c|}
\hline & & $B$ & $S E B$ & $\beta$ & $p$ \\
\hline \multicolumn{6}{|l|}{ Step 1} \\
\hline & Constant & 2.10 & .22 & & .00 \\
\hline & Self Efficacy & 0.35 & .06 & .31 & .00 \\
\hline \multicolumn{6}{|l|}{ Step 2} \\
\hline & Constant & 1.78 & .24 & & .00 \\
\hline & Self Efficacy & 0.24 & .07 & .22 & .00 \\
\hline & Self Direction Stimulus & 0.19 & .06 & .18 & .00 \\
\hline \multicolumn{6}{|l|}{ Step 3} \\
\hline & Constant & 1.59 & .26 & & .00 \\
\hline & Self Efficacy & 0.20 & .07 & .18 & .00 \\
\hline & Self Direction Stimulus & 0.17 & .06 & .16 & .00 \\
\hline & BFI Openness & 0.11 & .05 & .12 & .03 \\
\hline
\end{tabular}

Note. $R^{2}=.10$ for Step $1 ; \Delta R^{2}=.02$ for Step $2 ; \Delta R^{2}=.01$ for Step $3(p<.05)$.

The same analysis was conducted for the behavioral commitment, as presented in Table 10 . As the analysis revealed, only two predictors from the internal side seem relevant for behavioral commitment, with self-efficacy again taking on the role as the primal predictor with the highest amount of variance explained. The value security therein supplements Self-efficacy. Together these two predictors account for $R^{2}=.10$ of variance in regards to behavioral commitment. Concludingly, it can be stated that the set of predictors from the leadership perspective (see Figure 2 above) seems to possess a higher predictive validity, as it can account for a drastically higher amount of variance explained.

Table 10

Regression for Personality Variables and Behavioral Commitment

\begin{tabular}{llllll}
\hline & & $B$ & $S E B$ & $\beta$ & $p$ \\
\hline Step 1 & Constant & & & & \\
& Self Efficacy & 2.10 & .23 & & .00 \\
Step 2 & & 0.33 & .06 & .29 & .00 \\
& Constant & & & & .00 \\
& Self Efficacy & 1.81 & .25 & .22 & .00 \\
& Security & 0.25 & .06 & .00 & .00 \\
\hline
\end{tabular}

Note. $R^{2}=.08$ for Step $1 ; \Delta R^{2}=.02$ for Step $2(p<.01)$.

However, while this shows the general level of relevance of leadership variables (and partially personal variables) to the prediction of organizational commitment, a more holistic analysis aims to establish whether personality variables (including values) can explain variance in the leadership variables; thus, explaining whether the addition of these variables to the model allows for more accurate predictions of commitment. Again, as for the separate regression analyses, the calculations were computed separately for emotional and behavioral commitment to reveal their specific predictor sets.

The set of potential predictors for each of these analyses equals the sum of the analyses mentioned earlier, implying the individual factors of leadership, leadership communication quality, empowerment, personality factors, values, and self-efficacy. The regression analyses themselves followed a two-step approach: The first step was the (stepwise) entry of the leadership-related variables before in the second step the personality variables are entered in the same manner. This allows for analysis of the question, whether personality variables can explain variance leadership aspects. 
Table 11 presents the results for emotional commitment. As can be seen in Table 11, no additional variables were entered into the regression model. Thus, the aspects of personality, values, and self-efficacy could not explain any additional variance over the leadership variables. Thus, the final model of prediction of emotional commitment equals the one without personality variables entered in a second step. Personality (including values and self-efficacy) cannot add additional value to the prediction of this aspect of commitment.

Table 11

Complete Prediction Model for Emotional Commitment

\begin{tabular}{|c|c|c|c|c|c|}
\hline & & $B$ & $S E B$ & $\beta$ & $p$ \\
\hline \multicolumn{6}{|l|}{ Step 1} \\
\hline & Constant & 1.86 & .12 & & .00 \\
\hline & Perceived Leadership Communication Quality & 0.44 & .03 & .60 & .00 \\
\hline \multicolumn{6}{|l|}{ Step 2} \\
\hline & Constant & 1.24 & .16 & & .00 \\
\hline & Perceived Leadership Communication Quality & 0.32 & .03 & .44 & .00 \\
\hline & Empowerment & 0.30 & .05 & .27 & .00 \\
\hline \multicolumn{6}{|l|}{ Step 3} \\
\hline & Constant & 1.72 & .20 & & .00 \\
\hline & Perceived Leadership Communication Quality & 0.32 & .03 & .43 & .00 \\
\hline & Empowerment & 0.27 & .05 & .24 & .00 \\
\hline & Management by Exception & -.13 & .03 & -.16 & .00 \\
\hline \multicolumn{6}{|l|}{ Step 4} \\
\hline & Constant & 1.63 & .20 & & .00 \\
\hline & Perceived Leadership Communication Quality & 0.23 & .04 & .31 & .00 \\
\hline & Empowerment & 0.22 & .05 & .20 & .00 \\
\hline & Management by Exception & -0.13 & .03 & -.16 & .00 \\
\hline & Inspirational Motivation & 0.16 & .04 & .20 & .00 \\
\hline
\end{tabular}

Note. $R^{2}=.36$ for Step $1 ; \Delta R^{2}=.05$ for Step $2 ; \Delta R^{2}=.02$ for Step $3 ; \Delta R^{2}=.00$ for Step $4 ;(p<.01)$.

However, a vastly different situation presents itself with a gaze towards behavioral commitment (see Table 12). In behavioral commitment analysis, three additional variables explaining variance above the one explained by leadership aspects. The three values conformity, benevolence, and hedonism can explain additional variance and can be identified as significant predictors of behavioral commitment. This results in a total $R^{2}=.44-$ while this is similar in effect size to the prediction without personality variables - it is still clear that personal values add to the prediction (see Figure 3). 
Table 12

Complete Prediction Model for Behavioral Commitment

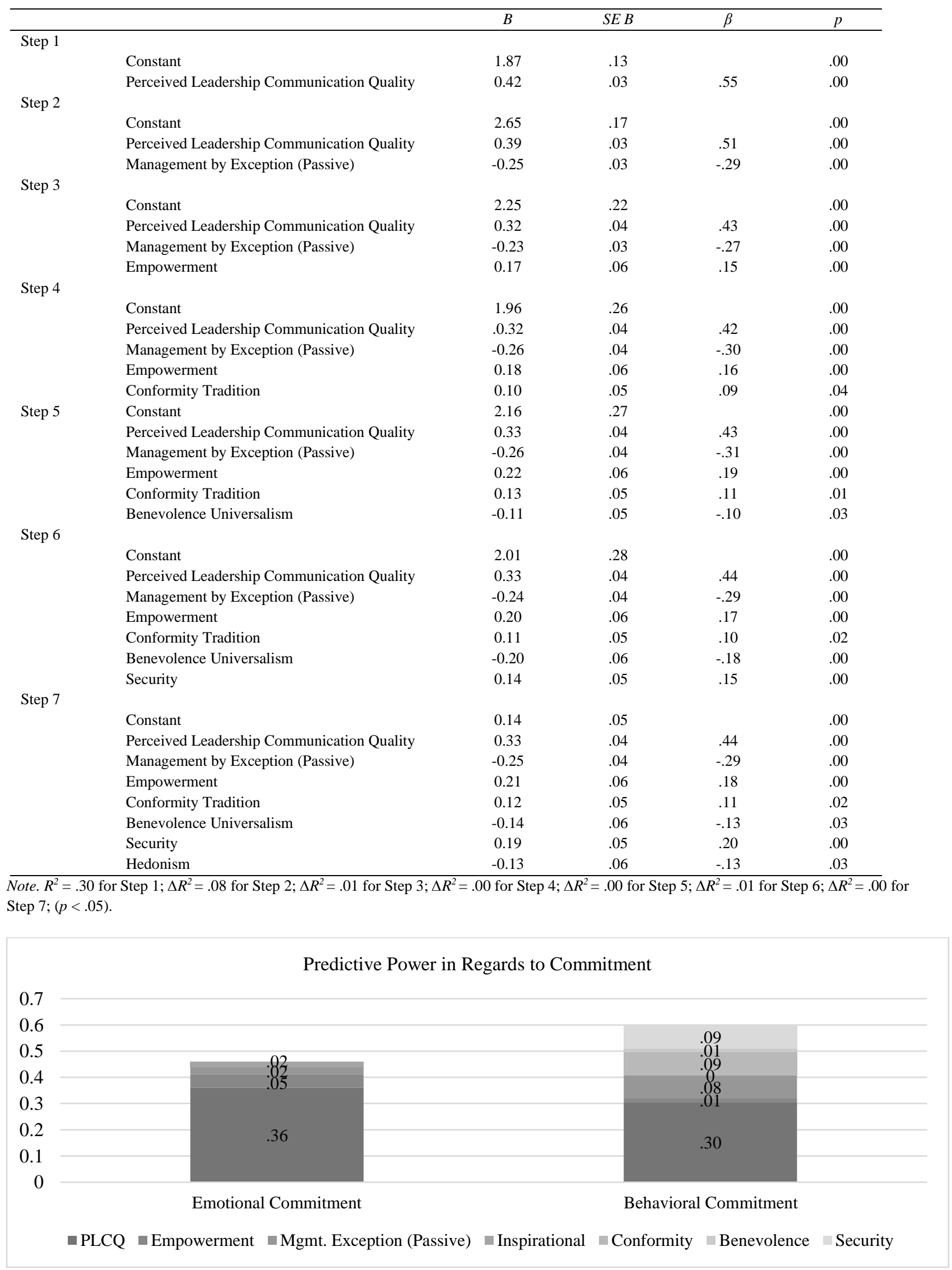

Figure 3. Summary of overall prediction results. 
Concludingly, the following conclusions can be made in regards to the research hypotheses described above:

The first hypothesis could be confirmed - leadership, in general, could be shown to be relevant both for emotional and behavioral commitment, with leadership communication quality taking on the role as dominant predictor among all models.

The second hypothesis could partially be confirmed: Both personality and values can predict variance in regards to commitment, although the effect seems to be more considerable on behavioral commitment, where values can account for additional variance above leadership.

The third hypothesis can only be confirmed for behavioral commitment: For emotional commitment, internal predictors (personality, values, self-efficacy) cannot explain additional variance above leadership. However, for behavioral commitment, values are significant predictors, with conformity, benevolence, and security being the relevant variables.

\section{Discussion}

\section{Main Findings and Research Contribution}

The present study built on existing work on organizational commitment (Allen \& Meyer, 1990, Meixner 2020a, Meixner 2020b) and the notion that commitment is a complex construct dependent both on aspects of the (leadership) environment on the one hand and on the committed person on the other hand. Thus, the study addressed the research gap described within the introduction of this paper that a majority of existing research on the topic usually shifts the focus on either one of those approaches: more social science-oriented publications (Ahluwalia \& Preet, 2018; Joo \& Shim, 2010; Srivastava, 2013) tend to highlight the role of personality and motivation, whereas typical leadership literature aims at fostering understanding of the interplay between leadership and management styles and commitment (Li, Sun, Taris, Xing, \& Peeters, 2020). Therein lays one of the limitations of research on organizational commitment - while individual papers typically confirm both the role of either personality factors or of leadership, respectively, a quantitative design utilizing measures for both perspectives presents itself to be the main contribution of the present paper. In this study, both perspectives were combined within one empirical approach that allowed for a meaningful comparison of the predictive validity of both aspects.

This comparison based on multiple linear regression analyses was conducted throughout this study, leading to an increased understanding of the relevance of leadership and personality aspects. While bi-variate and pairwise analyses showed significant relationships between leadership and commitment as well as between personality and values and commitment, multivariate analyses confirmed these results only partially. Regression analyses confirmed the influence of leadership and personality variables (including values) alike, only when entering separate regression models. In this case, the set of personality variables could account for significant contributions towards explaining variance regarding behavioral commitment. However, while this proved that leadership seems to be more impactful (given their higher amount of explained variance), it still left the question unclear whether the combined set of potential predictors confirms these findings.

The final multivariate analysis showed that for emotional commitment, only leadership variables acted as significant predictors - the personality and the values of participants were not 
able to account for additional variance in regards to the emotional commitment. For behavioral commitment, however, the relevance of personal values (Schwartz, 2012) could be confirmed: Three of the values assessed throughout the study were able to explain additional variance above the one explained by the leadership variables. Conformity, Benevolence, and Security were in these regards the three noteworthy values that seem to influence behavioral commitment even after accounting for leadership.

However, while the relevance of personal values could be confirmed within this work, it is still highlighted that leadership itself is the most valuable predictor, which brings with it according implications for practitioners.

Apart from transformational leadership itself, that is in multiple studies confirmed to be a predictor of various positive outcomes (such as motivation, well-being and commitment), the present study showed the high importance of leadership communication (De Vries, BakkerPieper, \& Oostenveld, 2010; Schneider et al., 2015) and the leadership tool empowerment (Chen, Kirkman, Kanfer, Allen, \& Rosen, 2007; Kark, Shamir, \& Chen, 2003). The empowerment of employees through their direct leaders is discussed by Ahearne, Mathieu, and Rapp (2005) as a tool of general transformational leadership. However, the present study shows that empowerment is even independently from general leadership, an important asset for strengthening employee commitment. The empirical results reveal that employees who feel empowered also tend to be more committed to their workplace and feel a stronger emotional attachment. Thus, the assumption presented in regards to the research of Choi, Goh, Adam, and Tan (2016) that leaders should increasingly use empowerment to strengthen their employees can be confirmed. This, in turn, has implications for the general leadership approach, where authors such as Kark, Shamir, and Chen (2003) argue that transformational leadership can either lead to a higher level of dependence by the staff towards their leader or a sense of empowerment. This work implies that the more beneficiary approach should be the one of empowerment, which strengthens commitment and raises the perceived self-efficacy of employees.

Furthermore, the present work indicates that when focusing solely on the statistical results that individual characteristics only play a minor role in predicting organizational commitment, which might imply, that leadership can be taken into consideration without a closer gaze towards the personalities and backgrounds of employees themselves. However, this would be a false conclusion as Bass and Steidlmeier (1999) or Kearney and Gebert (2009) argue that transformational leadership regarding the underlying leadership philosophy always actively considers the diversity of staff and the specific needs, motives, and desires of staff members. Therefore, it should be argued that transformational leadership and approaches close to it are not independent of the diversity of employees, but rather are one direct approach to addressing this diversity and acknowledging and fostering it. It apears that one possible reason for the surprisingly - low predictive power of personality and values in regards to the workplace might lay in the nature of these leadership approaches: Given that they, in an optimal case, already do take into account the personalities of their employees, these factors themselves might not be able to add additional value to the predictive model, as the diversity in these regards might already be depicted within the leadership variables.

However, it still stands out that values can account for unique variance regarding behavioral commitment - and not for emotional commitment. Emotional commitment mostly relies on leadership behavior, with leadership communication taking on the dominant predicting role. 
While this seems mostly true for the behavioral aspects too, it still becomes clear that employees' values actively add to the prediction model. Conformity, benevolence, and the need for security are relevant predictors for the actual behavioral commitment. This result seems to align with the very definitions of these values (Schmitt, Schwartz, Steyer, \& Schmitt, 1993; Schwartz, 2012; Schwartz et al., 2012). The need for conformity implies that employees might prefer to conform to their role and team (independent of their actual attitude) and show behaviors closely aligned with what the firm proposes. The need for security, a general definition (Schwartz, 2012) argues, should lead people to seek situations in which they are less challenged and that allows them for strengthened stability. Both these motives indicate that people scoring high on these values might seek to behave in a committed way. Their desire to conform and seek stability might independent of their environment - play an important role. This becomes clear with the distinction between emotional and behavioral commitment. While these motives/values do not necessarily influence employees' emotions, feelings, and thoughts about the workplace, they influence their behavior. This leads back to the model proposed by Meixner (2020a), who initially argued that norms and social values should most strongly affect normative commitment, a type of commitment not tested within this empirical model. However, the present results indicate a slight contradiction to this proposed model: Values also play a relevant role in behavioral outcomes, which are thus influenced by the relationship between employee and leader and the employees' characteristics.

\section{Limitations and Outlook}

The present study revealed the connection between leadership and commitment as influenced by aspects of personality and values. However, the findings are limited in terms of their geographical validity, as the study was only conducted within Germany. While the study aimed to include a wide variety of industries, to foster the generalizability of the findings, the geographical limitation still poses a threat to the external validity. It remains unclear whether the results reported here would hold true for other geographical and cultural regions. This, however, is identified to be a central point for subsequent research, especially in regards to research on cultural differences concerning values (Borg, Groenen, Jehn, Bilsky, \& Schwartz, 2011)

As proposed by Meixner (2020b), quantitative work on leadership and commitment typically suffers from the lack of a more diversified perspective. Quantitative research, such as the one conducted throughout this study, typically focuses on either the employee or the leader perspective but rarely manages to combine both perspectives within one study. While mixed method approaches (Creswell, 1999; Malina, Nørreklit, \& Selto, 2011) can be discussed as a remedy, which combines for example a quantitative approach accounting for the employee perspective with a qualitative approach for the leaders' and executives' perspectives, such a multimethod approach still does not allow for quantitative statements. In an optimal scenario, to foster understanding of the results presented throughout this study, combined samples (Barton, Lavner, Stanley, Johnson, \& Rhoades, 2020; Tambling, Johnson, \& Johnson, 2011) should be chosen. If leadership could be assessed not only in terms of perceived leadership (MLQ, Avolio \& Bass, 1996) but in actual leadership approach by combining the data of employees (measuring their commitment) with their genuine leader's behavior and approach, a significant benefit for research on the topic might arise. However, such an approach would require a paired sample that implies a dyadic approach to statistical analyses as it is known within social psychology (Kenny, Kashy, 
\& Cook, 2020) and a more complex approach to data acquisition itself. However, this approach seems too difficult to fabricate, as Rocco and Bush (2016) explain with a nod towards more experimental settings. Such settings, as they are, for example, described and discussed by Kenny, Kashy, and Cook (2020), allow for combating some of the shortcomings of typical empirical research on management. While studies such as the one conducted here (or by other authors such as Jackson, Meyer, \& Wang, 2013, Nasomboon, 2014) rely on observations and perceptions, experimental scenarios within management research are typically shown to have stronger internal validity. Due to the possibility of adjusting conditions accordingly and thus creating circumstances that allow for very detailed analyses of the impact of those variables, experimental settings tend to allow for a causal interpretation of findings (Gill, 1982). However, of course, the external validity of such lab studies tends to be limited (Banerjee, Chassang, \& Snowberg, 2017). While observational studies might suffer from lack of internal validity due to the heavy reliance on naturally occurring situations and perceptions, experimental settings suffer from a lack of external validity (Lusk, Pruitt, \& Norwood, 2006). The closely controlled laboratory settings that often go along with experimental designs do only partially allow for the generalization of those findings to real-world scenarios. Given the strong observation-based empirical foundation within leadership literature - with results such as the present ones confirming the general relevance of certain predictors and the validity of models - this trade-off might be a satisfactory one. Due to the high number of observational studies, the external validity of many findings could be observed from existing literature. Future research might benefit from experimental designs using approaches such as Wüst and Kuppinger (2012) or Tran (2012) to supplement the existing research landscape increasingly. Approaches such as those identified to be a possible contribution for future research - while the present study managed to assess the validity of the framework proposed, experimental designs might lead to additional knowledge gathered about the causal relationships between the individual variables.

Such experimental settings also might allow for assessment of less broad leadership approaches (Podsakoff \& Podsakoff, 2019). While researchers such as Bass (1999) or Nerdinger and Pundt (2018) argue that leaders typically follow distinct styles or approaches towards leadership, the dependence on the actual leadership situation is highlighted within the work of Neubauer, Bergner, and Felfe (2012) or Faraci, Lock, and Wheeler (2013). They argue that while leaders might have preferred approaches, they base their leadership actions strongly on the situation at hand in an optimal scenario. Experimental methods that allow for creating such scenarios would allow to observe actual leadership scenarios in light of specific situations and might lead to an increased understanding of how not only general leadership styles but also specific behaviors in critical situations might impact employees' perceptions.

\section{Conclusion}

Regarding the initially described research gap, it can be summarized that the present study was able to contribute knowledge about the interplay of personality variables and leadership. Especially the assessment of the predictive role personal values seems to take on in regard to the prediction of organizational commitment can be viewed as a major novelty supplemented by the quantitative approach utilized within this paper. This approach allowed the researcher to conduct a systematic comparison of the predictive power of different variables, with the main result being that above personality factors and personal values, it is mostly the perceived leadership behavior, 
that seems to impact organizational commitment. Thus, it can be concluded that leadership behavior even in comparison to variables such as personality and variables is the most important aspect of shaping employees' organizational commitment.

\section{References}

Abualoush, S. H., Obeidat, A. M., Tarhini, A., \& Al-Badi, A. (2018). The role of employees' empowerment as an intermediary variable between knowledge management and information systems on employees' performance. VINE Journal of Information and Knowledge Management Systems, 48(2), 217-237.

Ahearne, M., Mathieu, J., \& Rapp, A. (2005). To empower or not to empower your sales force? An empirical examination of the influence of leadership empowerment behavior on customer satisfaction and performance. Journal of Applied psychology, 90(5), 945-955.

Ahluwalia, A. K., \& Preet, K. (2018). Work motivation, organizational commitment and locus of control vis-a-vis work experience amongst university teachers. Samvad, 14, 26-33.

Allen, N. J., \& Meyer, J. P. (1990). The measurement and antecedents of affective, continuance and normative commitment to the organization. Journal of Occupational Psychology, 63(1), 1-18.

Arendt, J. F., Pircher Verdorfer, A., \& Kugler, K. G. (2019). Mindfulness and leadership: communication as a behavioral correlate of leader mindfulness and its effect on follower satisfaction. Frontiers in Psychology, 10, 667.

Avallone, F., Farnese, M. L., Pepe, S., \& Vecchione, M. (2010). The Work Values Questionnaire (WVQ): Revisiting Schwartz's Portrait Values Questionnaire (PVQ) for work contexts. BPA-Applied Psychology Bulletin (Bollettino di Psicologia Applicata), 261/262, 59-76.

Avolio, B. J., \& Bass, B. M. (1995). Individual consideration viewed at multiple levels of analysis: A multi-level framework for examining the diffusion of transformational leadership. The Leadership Quarterly, 6(2), 199-218.

Avolio, B. J., Bass, B. M., \& Jung, D. I. (1999). Re-examining the components of transformational and transactional leadership using the Multifactor Leadership. Journal of Occupational and Organizational Psychology, 72(4), 441-462.

Bandura, A. (2010). Self-efficacy. The Corsini Encyclopedia of Psychology, 1-3.

Banerjee, A. V., Chassang, S., \& Snowberg, E. (2017). Decision theoretic approaches to experiment design and external validity. In Handbook of Economic Field Experiments (Vol. 1, pp. 141-174). North-Holland.

Barbuto, J. E. (1997). Taking the charisma out of transformational leadership. Journal of Social Behavior and Personality, 12(3), 689-697.

Barbuto, J. E. (2005). Motivation and transactional, charismatic, and transformational leadership: A test of antecedents. Journal of Leadership \& Organizational Studies, 11(4), 26-40.

Bardy, R. (2018). Rethinking leadership: A human centered approach to management ethics. Routledge.

Barton, A. W., Lavner, J. A., Stanley, S. M., Johnson, M. D., \& Rhoades, G. K. (2020). Will you complete this survey too? Differences between individual versus dyadic samples in relationship research. Journal of Family Psychology, 34(2), 196203.

Bass, B. M. (1999). Two decades of research and development in transformational leadership. European Journal of Work and Organizational Psychology, 8(1), 9-32.

Bass, B. M., \& Avolio, B. J. (1996). Multifactor leadership questionnaire. European Journal of Psychological Assessment.

Bass, B. M., Avolio, B. J., \& Atwater, L. (1996). The transformational and transactional leadership of men and women. Applied Psychology, 45(1), 5-34.

Bass, B. M., \& Steidlmeier, P. (1999). Ethics, character, and authentic transformational leadership behavior. The Leadership Quarterly, 10(2), 181-217.

Becker, T. E., Billings, R. S., Eveleth, D. M., \& Gilbert, N. L. (1996). Foci and bases of employee commitment: Implications for job performance. Academy of Management Journal, 39(2), 464-482.

Borg, I., Groenen, P. J., Jehn, K. A., Bilsky, W., \& Schwartz, S. H. (2011). Embedding the organizational culture profile into Schwartz's theory of universals in values. Journal of Personnel Psychology, 10(1), 1-12.

Buil, I., Martínez, E., \& Matute, J. (2019). Transformational leadership and employee performance: The role of identification, engagement and proactive personality. International Journal of Hospitality Management, 77, 64-75. 
Carlson, K. D., \& Herdman, A. O. (2012). Understanding the impact of convergent validity on research results. Organizational Research Methods, 15(1), 17-32.

Chen, G., Kirkman, B. L., Kanfer, R., Allen, D., \& Rosen, B. (2007). A multilevel study of leadership, empowerment, and performance in teams. Journal of applied psychology, 92(2), 331-346.

Choi, S. L., Goh, C. F., Adam, M. B. H., \& Tan, O. K. (2016). Transformational leadership, empowerment, and job satisfaction: the mediating role of employee empowerment. Human Resources for Health, 14(1), 73.

Cieciuch, J., \& Schwartz, S. H. (2012). The number of distinct basic values and their structure assessed by PVQ-40. Journal of Personality Assessment, 94(3), 321-328.

Cohen, J. (1992). A power primer. Psychological Bulletin, 112(1), 155-159.

Cohen, A., \& Liu, Y. (2011). Relationships between in-role performance and individual values, commitment, and organizational citizenship behavior among Israeli teachers. International Journal of Psychology, 46(4), 271-287.

Creswell, J. W. (1999). Mixed-method research: Introduction and application. In Handbook of educational policy (pp. $455-$ 472). Academic Press.

Deci, E. L., \& Ryan, R. M. (2010). Intrinsic motivation. The Corsini Encyclopedia of Psychology, 1-2.

de Vet, H. C., Mokkink, L. B., Mosmuller, D. G., \& Terwee, C. B. (2017). Spearman-Brown prophecy formula and Cronbach's alpha: different faces of reliability and opportunities for new applications. Journal of Clinical Epidemiology, $85,45-49$.

De Vries, R. E., Bakker-Pieper, A., \& Oostenveld, W. (2010). Leadership= communication? The relations of leaders' communication styles with leadership styles, knowledge sharing and leadership outcomes. Journal of Business and Psychology, 25(3), 367-380.

Ebrahimi, P., Rezvani Chamanzamin, M., Roohbakhsh, N., \& Shaygan, J. (2017). Transformational and transactional leadership: Which one is more effective in the education of employees' creativity? Considering the moderating role of learning orientation and leader gender. International Journal of Organizational Leadership, 6, 137-156.

Esenyel, V. (2020). Corporate reputation as a strategic management tool: Through the lens of employees. International Journal of Management and Sustainability, 9(1), 24-42.

Faraci, P., Lock, M., \& Wheeler, R. (2013). Assessing leadership decision-making styles: Psychometric properties of the leadership Judgement indicator. Psychology Research and Behavior Management, 6, 117-123.

Fischer, H. R., Stahl, H. K., Schettgen, P., \& Schlipat, H. (2019). Einleitung der Herausgeber. [Editors' introduction] In R. Fischer, H. K. Stahl, P. Schettgen, \& H. Schlipat (Eds.), Dienende Führung. Zu einer neuenBalance zwischen ICH und WIR [Servant Leadership. About a new balance between I and WE] (P. 1-4). Berlin: Erich Schmidt Verlag GmbH \& Co.

Gill, J. (1982). Research as action: An experiment in utilising the social sciences. Personnel Review, 11(2), 25-34.

Goldberg, L. R. (1990). An alternative" description of personality": The big-five factor structure. Journal of personality and social psychology, 59(6), 1216-1229.

Griffith, K. (2019). Characterizing the 'global war for talent'. In Research Handbook of International Talent Management. Edward Elgar Publishing.

Hater, J. J., \& Bass, B. M. (1988). Superiors' evaluations and subordinates' perceptions of transformational and transactional leadership. Journal of Applied Psychology, 73(4), 695-702.

Hayati, B., Atefi, Y., \& Ahearne, M. (2018). Sales force leadership during strategy implementation: a social network perspective. Journal of the Academy of Marketing Science, 46(4), 612-631.

Hayes, B. E. (1994). How to measure empowerment. Quality Progress, 27, 41-41.

Haynes, S. (2017). Nudge theory, gamification and e-assessments: the future of employee wellbeing technology? Occupational Health \& Wellbeing, 69(11), 11-13.

Howell, J. M., \& Avolio, B. J. (1993). Transformational leadership, transactional leadership, locus of control, and support for innovation: Key predictors of consolidated-business-unit performance. Journal of Applied Psychology, 78(6), 891902.

Jackson, D., Hutchinson, M., Peters, K., Luck, L., \& Saltman, D. (2013). Understanding avoidant leadership in health care: findings from a secondary analysis of two qualitative studies. Journal of Nursing Management, 21(3), 572-580.

Jackson, T. A., Meyer, J. P., \& Wang, X. H. (2013). Leadership, commitment, and culture: A meta-analysis. Journal of Leadership \& Organizational Studies, 20(1), 84-106.

Jensen, U. T., \& Bro, L. L. (2018). How transformational leadership supports intrinsic motivation and public service motivation: The mediating role of basic need satisfaction. The American Review of Public Administration, 48(6), 535549. 
Jia, X., Liao, S., Van der Heijden, B. I., \& Guo, Z. (2019). The effect of socially responsible human resource management (SRHRM) on frontline employees' knowledge sharing. International Journal of Contemporary Hospitality Management, 31(9), 3646-3663.

Joo, B. K., \& Shim, J. H. (2010). Psychological empowerment and organizational commitment: the moderating effect of organizational learning culture. Human Resource Development International, 13(4), 425-441.

Judge, T. A., \& Piccolo, R. F. (2004). Transformational and transactional leadership: a meta-analytic test of their relative validity. Journal of Applied Psychology, 89(5), 755-768.

Kark, R., Shamir, B., \& Chen, G. (2003). The two faces of transformational leadership: Empowerment and dependency. Journal of Applied Psychology, 88(2), 246-255.

Kearney, E., \& Gebert, D. (2009). Managing diversity and enhancing team outcomes: the promise of transformational leadership. Journal of Applied Psychology, 94(1), 77-89.

Keller, S., \& Meaney, M. (2017). Attracting and retaining the right talent. McKinsey Global Institute study.

Kenny, D. A., Kashy, D. A., \& Cook, W. L. (2020). Dyadic data analysis. Guilford press.

Kidron, A. (1978). Work values and organizational commitment. Academy of Management Journal, 21(2), $239-247$.

Leclerc, L., Kennedy, K., \& Campis, S. (2020). Human-centered leadership in health care: An idea that's time has come. Nursing Administration Quarterly, 44(2), 117-126.

Li, P., Sun, J. M., Taris, T. W., Xing, L., \& Peeters, M. C. (2020). Country differences in the relationship between leadership and employee engagement: A meta-analysis. The Leadership Quarterly, 101458.

Liu, Y., \& Cohen, A. (2010). Values, commitment, and OCB among Chinese employees. International Journal of Intercultural Relations, 34(5), 493-506.

Lopez-Cabrales, A., \& Valle-Cabrera, R. (2020). Sustainable HRM strategies and employment relationships as drivers of the triple bottom line. Human Resource Management Review, 30(3), 100689.

Lusk, J. L., Pruitt, J. R., \& Norwood, B. (2006). External validity of a framed field experiment. Economics Letters, 93(2), 285-290.

Ma, Y. J., \& Lee, H. H. (2012). Understanding consumption behaviours for fair trade non-food products: focusing on selftranscendence and openness to change values. International Journal of Consumer Studies, 36(6), 622-634.

Macey, W. H., \& Schneider, B. (2008). The meaning of employee engagement. Industrial and Organizational Psychology, $1(1), 3-30$.

MacKenzie, S. B., Podsakoff, P. M., \& Rich, G. A. (2001). Transformational and transactional leadership and salesperson performance. Journal of the Academy of Marketing Science, 29(2), 115-134.

Malina, M. A., Nørreklit, H. S., \& Selto, F. H. (2011). Lessons learned: Advantages and disadvantages of mixed method research. Qualitative Research in Accounting \& Management, 8(1), 59-71.

McCleskey, J. A. (2014). Situational, transformational, and transactional leadership and leadership development. Journal of Business Studies Quarterly, 5(4), 117-130.

Meixner, T. (2020a). Organizational commitment: Re-structuring a concept crucial for management and leadership using a confirmatory factor analysis. International Journal of Organizational Leadership, 9(2), 77-92.

Meixner, T. (2020b). Personality, perceived leadership and commitment. Presented in the European Scientific Conference of Doctoral Students (p. 127). Mendel University, Brno.

Nasomboon, B. (2014). The relationship among leadership commitment, organizational performance, and employee engagement. International Business Research, 7(9), 77-99.

Nerdinger, F. W., \& Pundt, A. (2018). Leadership of service employees-A narrative review. SMR-Journal of Service Management Research, 2(1), 3-15.

Neubauer, A. C., Bergner, S., \& Felfe, J. (2012). Leadership Judgement Indicator (LJI). Deutschsprachige Adaptation des Leadership Judgement Indicator (LJI) von M. Lock und R. Wheeler.

Özaralli, N. (2003). Effects of transformational leadership on empowerment and team effectiveness. Leadership \& Organization Development Journal, 24(6), 335-344.

Pajares, F. (1997). Current directions in self-efficacy research. Advances in Motivation and Achievement, 10(149), 1-49.

Podsakoff, P. M., \& Podsakoff, N. P. (2019). Experimental designs in management and leadership research: Strengths, limitations, and recommendations for improving publishability. The Leadership Quarterly, 30(1), 11-33.

Pretsch, J., Pretsch, E., Saretzki, J., Kraus, H., \& Grossmann, G. (2020). Improving employee well-being by means of virtual reality-REALEX: An empirical case study. European Journal of Economics and Business Studies, 6(1), 95-105. 
Rammstedt, B., \& John, O. P. (2007). Measuring personality in one minute or less: A 10-item short version of the Big Five Inventory in English and German. Journal of Research in Personality, 41(1), 203-212.

Rhee, J., Seog, S. D., Bozorov, F., \& Dedahanov, A. T. (2017). Organizational structure and employees' innovative behavior: The mediating role of empowerment. Social Behavior and Personality: an international journal, 45(9), 1523-1536.

Rocco, R. A., \& Bush, A. J. (2016). Exploring buyer-seller dyadic perceptions of technology and relationships. Journal of Research in Interactive Marketing, 10(1), 17-32.

Russell, J. A. (1978). Evidence of convergent validity on the dimensions of affect. Journal of Personality and Social Psychology, 36(10), 1152-1168.

Saks, A. M. (2006). Antecedents and consequences of employee engagement. Journal of Managerial Psychology, 21(7), 600-619.

Sarros, J. C., \& Santora, J. C. (2001). The transformational-transactional leadership model in practice. Leadership \& Organization Development Journal, 22(8), 383-394

Schmitt, M. J., Schwartz, S., Steyer, R., \& Schmitt, T. (1993). Measurement models for the Schwartz values. European Journal of Psychological Assessment, 9(2), 107-121.

Schneider, F. M., Maier, M., Lovrekovic, S., \& Retzbach, A. (2015). The perceived leadership communication questionnaire (PLCQ): Development and validation. The Journal of Psychology, 149(2), 175-192.

Schwartz, S. H. (2012). An overview of the Schwartz theory of basic values. Online readings in Psychology and Culture, 2(1), 2307-0919.

Schwartz, S. H., Cieciuch, J., Vecchione, M., Davidov, E., Fischer, R., Beierlein, C., ... \& Dirilen-Gumus, O. (2012). Refining the theory of basic individual values. Journal of Personality and Social Psychology, 103(4), 663-688.

Sherer, M., \& Adams, C. H. (1983). Construct validation of the self-efficacy scale. Psychological Reports, 53(3), 899-902.

Srivastava, S. (2013). Job satisfaction and organizational commitment relationship: Effect of personality variables. Vision, 17(2), 159-167.

Stahl, H. K. (2013). Führungswissen [Leadership Knowledge]. Berlin: Erich Schmidt Verlag GmbH \& Co. KG.

Stewart, J. (2006). Transformational leadership: An evolving concept examined through the works of Burns, Bass, Avolio, and Leithwood. Canadian Journal of Educational Administration and Policy, (54).

Tambling, R. B., Johnson, S. K., \& Johnson, L. N. (2011). Analyzing dyadic data from small samples: A pooled regression actor-partner interdependence model approach. Counseling Outcome Research and Evaluation, 2(2), $101-114$.

Tavakol, M., \& Dennick, R. (2011). Making sense of Cronbach's alpha. International Journal of Medical Education, 2, 5355 .

Tran, V. (2012). Emotions and decision-making processes in management teams: a collective level analysis. Journal of Work and Organizational Psychology, 28(1), 15-24.

Vaske, J. J., Beaman, J., \& Sponarski, C. C. (2017). Rethinking internal consistency in Cronbach's alpha. Leisure Sciences, 39(2), 163-173.

Wüst, K., \& Kuppinger, B. (2012). Is everything just a game? From the discrete to the continuous time modeling of corporate strategy games. Journal of Management Control, 23(3), 211-228.

Zimmerman, M. A. (2000). Empowerment theory. In Handbook of community psychology (pp. 43-63). Springer, Boston, MA. 